\title{
Conformational study of HGV-NS3 (440-460) by circular dichroism (CD). Effect of lipophillic derivation on CD spectra
}

\author{
N. Rojo, M.A. Alsina ${ }^{1}$ and I. Haro \\ Department of Peptide \& Protein Chemistry, I/QAB-CSIC, Jordi Girona 18-26, 08034 Barcelona, \\ Spain \\ ${ }^{1}$ Department of Physicochemistry, Faculty of Pharmacy, University of Barcelona, \\ Av. Joan XXIII, s/n, 08028 Barcelona, Spain
}

\begin{abstract}
The present study was undertaken to examine the conformation by Circular Dichroism spectroscopy of the (440-460): AIAYYRGKDSSIIKDGDLVVC peptide sequence belonging to the non-structural protein (NS3) of hepatitis $\mathrm{G}$ virus (HGV). The conformation of free HGV-NS3(440-460) and two lipophilic derivates at the Nterminus with palmitic and miristic acids respectively, was studied at different concentrations in HEPES as well as in the presence of the most commonly used agents for stabilizing conformations (TFE,HFIP)
\end{abstract}

\section{INTRODUCTION}

The Hepatitis G virus (HGV) was first identified in 1994 from the plasma of a patient with etiologically unexplained chronic hepatitis. The Hepatitis $G$ virus belongs to the family of Flaviviridae [1].

HGV infections were detected in approx. 1-2\% of the general population and in up to $30 \%$ of risk groups (e.g. drug addicts). HGV can be transmitted parenterally and sexually and from an HGV infected mother to her child. The majority of HGV-infected individuals has no clinical or biochemicals evidence of liver disease. However, there are cases of acute including fulminant hepatitis and chronical hepatitis with their sequelae where $\mathrm{HGV}$ is the only recognizable cause of liver disease [2].

The 5'-end of the genome codes for two structural proteins: E1 and E2, the non-structural proteins NS2,NS3,NS4, NS5a and NS5b being located at the 3'-terminal region.

Dichroism spectroscopy has widely been used to estimate secondary structure content of peptides and proteins in solution $[3,4]$. In the present study we examine the conformation by circular dichroism spectroscopy of the (440-460) peptide sequence belonging to the NS3 protein of HGV, in order to understand the structural features that may be important to explain its antigenicity.

\section{EXPERIMENTAL PART}

\subsection{Peptide Synthesis}

Peptides were synthesized manually on a Rink amide MBHA $(0.75 \mathrm{meq} / \mathrm{g})$ resin by solid phase methodology following a 9-Fluorenylmethoxycarbonyl (Fmoc)/ tert-butyl (tBut) strategy by means of a $\mathrm{N}, \mathrm{N}$ ' -diisopropylcarbodiimide (DIPCD)/1-hidroxybenzotriazole (HOBt) activation.

Side protection was effected by the following: 2,2,5,7,8-pentamethyl-chroman-6-sulfonyl (Pmc) for Arg; tert-Butyl (tBut) for Asp, Ser and Tyr; triphenylmethyl (Trt) for Cys; and t-Butoxycarbonyl (Boc) for Lys.

Threefold molar excesses of Fmoc-amino acids were used throughout the synthesis. The stepwise addition of each residue was assessed by the Kaiser's (ninhydrin) test. Deprotection was performed in $20 \%$ piperidine/DMF.

Different conditions were tested to cleave the peptide from the resin and to remove the side-chain blocking groups. Overall, peptide resins were treated with TFA solutions containing appropiate scavengers $\left(5 \% \mathrm{H}_{2} \mathrm{O}, 3 \%\right.$ ethanedithiol, $5 \%$ anisol).

Crude peptides were purified by preparative high performance liquid chromatography (HPLC) on a Shimadzu chromatograph equipped with a $\mathrm{C}_{18}$-silica column. Purified peptides were characterized by 
analytical HPLC, amino acid analysis and electrospray mass spectrometry.

\subsection{Spectroscopy Experiments}

CD spectra were recorded on a Jasco J720 spectropolarimeter. Measurements were done in $5 \mathrm{mM} \mathrm{N}$-(2hydroxyethyl) piperazine-N'-ethanesulfonic acid (HEPES) buffer pH 7.4; 2,2,2-Trifluoroethanol (TFE); Hexafluoroisopropanol (HFIP) and sodium dodecylsulfate (SDS).

Cells $0.1 \mathrm{~cm}$ in diameter were used and peptide concentration was determined in duplicate both spectrophotometrically using extinction coefficients of Tyr, Cys [5]; and by quantitative amino acid analysis. Concentration determined by these two independent methods differed from each other by less than $5 \%$.

Measurements were performed at $5^{\circ} \mathrm{C}$ and the data were expressed in terms of mean residue ellipticities $[\theta]\left(\mathrm{deg} . \mathrm{cm}^{2} \cdot \mathrm{dmol}{ }^{-1}\right)$. Three scans were accumulated to improve the signal to noise ratio. Before reading the peptide spectra, a blank spectrum of the buffer solution was subtracted.

The spectra were measured between 190 and $260 \mathrm{~nm}$ using a spectral bandwidth of a $1 \mathrm{~nm}$ and a scan speed of $10 \mathrm{~nm} / \mathrm{min}$. K2D, Contin and Lincomb programs were used to quantitate experimental $\mathrm{CD}$ results in a $\mathrm{PC}$-compatible computer [6].

\section{RESULTS AND DISCUSSION}

Initial $\mathrm{CD}$ experiments were carried out at $5^{\circ} \mathrm{C}$ in HEPES buffer. In this medium free NS3 peptide exhibits a large negative band near $195 \mathrm{~nm}$ characteristic of a random coil conformation. Next, the effect of adding $\alpha$-helix promoting solvents (TFE and HFIP) was analyzed for the comparison of the corresponding CD spectra [7]. As shown in Figure. 1 in the presence of these solvents, the peptide adopts a larger proportion of secondary structure. Accordingly by the deconvolution of the spectra by LincombBrahms computer programs shown in Table. $I$ the content of $\alpha$-structure conformation achieved values between 18.5 and $24 \%$.

\begin{tabular}{|c|c|c|c|}
\hline \multicolumn{4}{|c|}{$\operatorname{NS} 3(440.460)$} \\
\hline Structure & HEPES & $50 \%$ TFE & $50 \%$ HFIP \\
\hline$\alpha$-Helix & 6.9 & 24.1 & 18.5 \\
\hline$\beta$-Sheet & 29.3 & 29.8 & 30.5 \\
\hline$\beta$ Tum & 10.9 & 8.4 & 1.2 \\
\hline Random Coil & 52.7 & 37.5 & 49.6 \\
\hline \multicolumn{4}{|c|}{ Palmitoyl-NS3(440-460) } \\
\hline Structure & HEPES & $50 \%$ TFE & $50 \% \mathrm{HFIP}$ \\
\hline$\alpha$-Helix & 24.1 & 30.6 & 4.8 \\
\hline$\beta$-Sheet & 29.8 & 7.9 & 54.4 \\
\hline$\beta-T u m$ & 8.4 & 23.5 & 1.5 \\
\hline Random Coil & 37.5 & 37.7 & 39.1 \\
\hline \multicolumn{4}{|c|}{ Miristoyl-NS3(440-460) } \\
\hline Structure & HEPES & $50 \%$ TFE & $50 \% \mathrm{HFIP}$ \\
\hline$\alpha$-Helix & 4.6 & 15.2 & 3.7 \\
\hline$\beta$-Sheet & 45.6 & 35.9 & 54.5 \\
\hline$\beta$-Turn & 9.8 & 4.0 & 1.5 \\
\hline Random Coil & 39.7 & 44.7 & 40.2 \\
\hline
\end{tabular}

Table 1. Analysis of NS3(440-460), pal-NS3(440-460) and mir-NS3(440-460) in Hepes buffer, TFE and HFIP by LincombBrahms Computer Program.

Palmitoyl and miristoyl-NS3 derivatives showed a different behavior that the parent peptide as reported by others authors [8]. CD experiments of hydrophobic peptides in Hepes yielded a higher content in 
ordered conformations (Table. 1 and Figures. 2-3). Moreover in $50 \%$ of TFE medium higher $\alpha$-helix conformations were evaluated when using Lincomb-Brahms deconvolution program. On the other hand in $50 \%$ of HFIP $\beta$-type structures were preferently quantified.

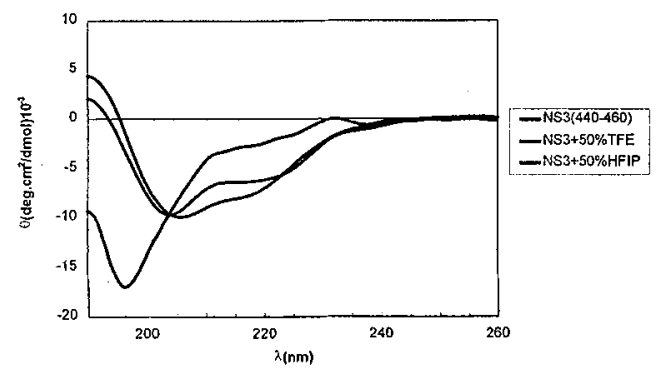

Figure 1. CD spectra of $30 \mu \mathrm{M}$ NS3(440-460) peptide in HEPES buffer, TFE and HFIP.

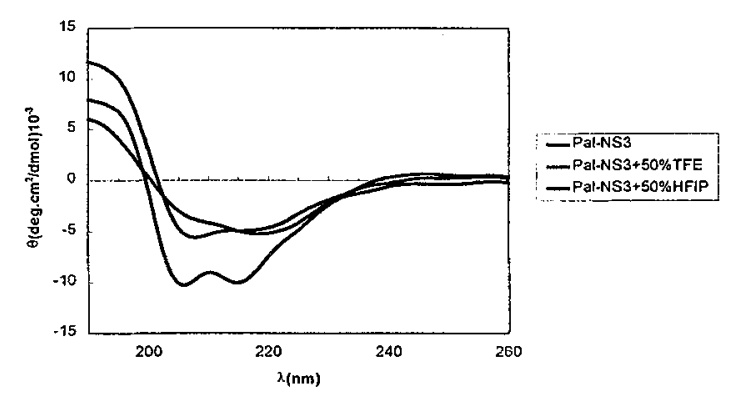

Figure 2. CD spectra of $30 \mu \mathrm{M}$ pal-NS3(440-460) peptide in HEPES buffer, TFE and HFIP.

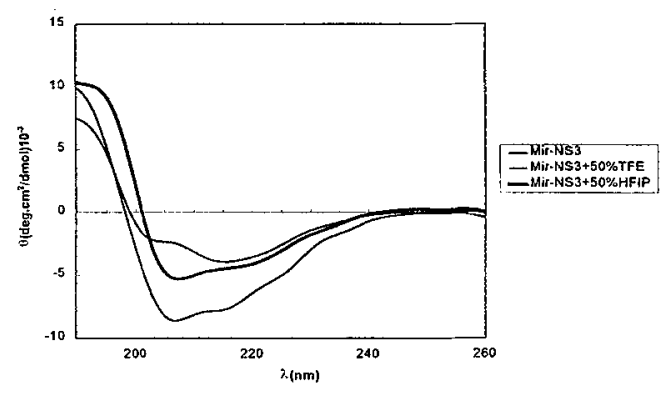

Figure 3. CD spectra of $30 \mu \mathrm{M}$ mir-NS3(440-460) peptide in HEPES buffer, TFE and HFIP.

\section{References}

[1] K. Kiyosawa, E.Tanaka, Intervirology 42(1999) 185-195.

[2] M. Tacke, K. Kiyosawa, K.Stark, V. Schlueter, B. Ofenloch-Haelhnle, G. Hess, A. Engel, The Lancet 349 (1997) 318-320.

[3] J.A.Pérez, J. Cantó, F.Reig, J.J.Perez, I.Haro. Biopolymers 45 (1998) 479-492.

[4] N.J. Greenfield. Anal Biochem 235 (1996) 1-10.

[5] M.M.Juban, M.M.Javadpour, M.D.Barkley. Methods Mol Biol 78 (1997) 73-79.

[6] M.J.Gómara, V.Girona, G.Ercilla, F.Reig, M.A. Alsina, I. Haro. Biopolymers 58 (2001) 117-128.

[7] A.Dong, J.Matsuura, M.C.Manning, J.F.Carpenter. Arch. Biochem and Biophys 355 (1998) 275-281.

[8] I.Laczkó, M.Hollósi, E.Vass, G. Tóth. Biochem and Biophis Res Commun. 249 (1998) 213-217. 